\title{
Nonhost Resistance in Arabidopsis-Colletotrichum Interactions Acts at the Cell Periphery and Requires Actin Filament Function
}

\author{
Chiyumi Shimada, ${ }^{1}$ Volker Lipka, ${ }^{2}$ Richard O'Connell, ${ }^{3}$ Tetsuro Okuno, ${ }^{1}$ Paul Schulze-Lefert, ${ }^{3}$ and \\ Yoshitaka Takano'
}

${ }^{1}$ Graduate School of Agriculture, Kyoto University, Kyoto, Japan; ${ }^{2}$ Center for Plant Molecular Biology, University of Tübingen, Tübingen, Germany; ${ }^{3}$ Max Planck Institute for Plant Breeding Research, Cologne, Germany

Submitted 8 August 2005. Accepted 17 October 2005.

Pathogenesis of nonadapted fungal pathogens is often terminated coincident with their attempted penetration into epidermal cells of nonhost plants. The genus Colletotrichum represents an economically important group of fungal plant pathogens that are amenable to molecular genetic analysis. Here, we investigated interactions between Arabidopsis and Colletotrichum to gain insights in plant and pathogen processes activating nonhost resistance responses. Three tested nonadapted Colletotrichum species differentiated melanized appressoria on Arabidopsis leaves but failed to form intracellular hyphae. Plant cells responded to Colletotrichum invasion attempts by the formation of PMR4/GSL5dependent papillary callose. Appressorium differentiation and melanization were insufficient to trigger this localized plant cell response, but analysis of nonpathogenic $C$. lagenarium mutants implicates penetration-peg formation as the inductive cue. We show that Arabidopsis PEN1 syntaxin controls timely accumulation of papillary callose but is functionally dispensable for effective preinvasion (penetration) resistance in nonhost interactions. Consistent with this observation, green fluorescent protein-tagged PEN1 did not accumulate at sites of attempted penetration by either adapted or nonadapted Colletotrichum species, in contrast to the pronounced focal accumulations of PEN1 associated with entry of powdery mildews. We observed extensive reorganization of actin microfilaments leading to polar orientation of large actin bundles towards appressorial contact sites in interactions with the nonadapted Colletotrichum species. Pharmacological inhibition of actin filament function indicates a functional contribution of the actin cytoskeleton for both preinvasion resistance and papillary callose formation. Interestingly, the incidence of papilla formation at entry sites was greatly reduced in interactions with $C$. higginsianum isolates, indicating that this adapted pathogen may suppress preinvasion resistance at the cell periphery.

Nonhost resistance can be defined as immunity displayed by an entire plant species against all genetic variants of a pathogen species and thus affects the host range of a pathogen (Heath 2000). This type of immunity is durable and common in nature but is still poorly understood in comparison with disease resistance exhibited by specific plant genotypes within an otherwise susceptible host species. This latter form of plant

Corresponding author: Y. Takano; E-mail: ytakano@kais.kyoto-u.ac.jp immunity is triggered upon direct or indirect recognition of cognate race-specific resistance $(\mathrm{R})$ proteins and isolate-specific avirulence gene products in the host and pathogen, respectively (Flor 1971; Martin 1999). Race-specific immunity is usually associated with the activation of a localized cell-death response, while attacked cells in nonhost interactions normally remain alive. It is likely that constitutive physical and chemical barriers on the plant surface represent components of nonhost resistance. However, in nonhost interactions, plants can also mount a battery of induced barriers against pathogen infection (Thordal-Christensen 2003).

One example of a putative inducible structural barrier against pathogen ingress are localized cell-wall appositions (CWA) in the paramural space (inner side of cell walls), often called papillae. These molecularly complex structures are usually formed directly beneath contact sites of fungal appressoria or bacterial adhesion sites (Brown et al. 1998; Jacobs et al. 2003; Nishimura et al. 2003; Thordal-Christensen et al. 1997). An oxidative microburst accompanies CWA formation at the plasma membrane (Thordal-Christensen et al. 1997). Plant cells also appear to direct the delivery of small antimicrobial molecules and proteins to these pathogen contact sites on the cell surface, possibly using polarized vesicle-associated secretory processes (Schulze-Lefert 2004). Recently, PEN1 of Arabidopsis was identified as one factor of nonhost resistance against the barley powdery mildew, Blumeria graminis f. sp. hordei (Collins et al. 2003). PEN1 encodes a plasma membrane-resident syntaxin (Collins et al. 2003). Syntaxins are members of the SNARE superfamily of proteins that mediate membrane fusion events. PEN1 is recruited to a plasma membrane microdomain beneath powdery mildew appressoria and might function in the tethering of intracellular vesicles and discharge of vesicle cargo at the cell periphery (Assaad et al. 2004; Bhat et al. 2005). In the pen 1-1 mutant, papilla formation is delayed (Assaad et al. 2004), indicating the potential involvement of PEN1 in timely deposition of cell wall material in the paramural space in response to attempted B. graminis f. sp. hordei invasion.

In the past, nonhost resistance to fungal parasites has been mainly examined by cytological and pharmacological studies in interactions with obligate biotrophic pathogens such as powdery mildews and rust fungi. In interactions with the powdery mildew fungus, enzymatic digestion of the cell wall most likely assists cell wall penetration, and fungal nutrient uptake strictly depends on living plant cells at infection sites via specialized feeding structures, designated haustorial complexes. Fungal haustoria are formed by invagination of the plasma 
membrane subsequent to cell wall penetration of attacked leaf epidermal cells. In contrast to biotrophic fungal pathogens, necrotrophic fungi kill host cells and obtain nutrients from dying host cells. Interestingly, some fungal pathogens utilize both biotrophic and necrotrophic nutrition at different stages of their development (Perfect et al. 1999). Such parasites are called hemibiotrophs, i.e., these pathogens initially develop inside living host cells and subsequently switch to a destructive necrotrophic phase of infection. At present, knowledge of nonhost resistance responses to necrotrophs and hemibiotrophs is limited.

The large ascomycete genus Colletotrichum is one of the most economically important groups of plant pathogens, causing anthracnose disease on a wide range of crops (Agrios 1988). Many Colletotrichum species have evolved a hemibiotrophic strategy for plant colonization (Perfect et al. 1999). Colletotrichum species develop appressoria that are essential for penetration into host plants. Like appressoria of Magnaporthe species, those of Colletotrichum species are pigmented with melanin, which is required for appressorium function (Yamaguchi and Kubo 1992). Melanized but not nonmelanized appressoria can generate the high turgor pressure necessary for mechanical penetration through the plant cuticle and cell wall (Bechinger et al 1999; Howard et al. 1991). Colletotrichum species have the advantage of being haploid organisms, which can be cultured axenically and genetically transformed. This greatly facilitates mutational analysis and the critical assessment of gene function by targeted gene disruption. Recently, it has been reported that isolates of C. destructivum and C. higginsianum infect Arabidopsis thaliana (Narusaka et al. 2004; O'Connell et al. 2004). This finding provides a new model pathosystem between Arabidopsis and Colletotrichum species, in which both partners in the interaction can be genetically manipulated.

In this report, we examined nonhost resistance responses of $A$. thaliana to various nonadapted Colletotrichum species. Nonhost resistance is manifested by termination of fungal pathogenesis coincident with fungal entry into leaf epidermal cells, without death of the attacked cells. Microscopic analysis revealed that this preinvasion resistance is linked to the accumulation of papillary callose beneath fungal appressoria. By using several nonpathogenic mutants of a nonadapted Colletotrichum species, we show that penetration-peg formation but not appressorium development serves as the major trigger for nonhost resistance responses at the cell periphery. Using plants expressing a PEN1green fluorescent protein (GFP) fusion and a penl mutant, we show that the Arabidopsis PEN1 syntaxin is not essential for preinvasion resistance to Colletotrichum species. We also utilized a transgenic Arabidopsis line expressing a chimeric GFPmouse talin gene to visualize actin cytoskeleton dynamics during papilla formation and employed a pharmacological approach to provide evidence for actin filament function in nonhost disease resistance. We conclude from a comparative analysis of Arabidopsis interactions involving both nonadapted and adapted Colletotrichum species that the latter may have evolved means to suppress nonhost resistance responses at the cell periphery.

\section{RESULTS}

\section{Nonadapted Colletotrichum species fail}

to enter attacked Arabidopsis epidermal cells.

Isolates of the brassica anthracnose pathogen $C$. higginsianum were recently reported to be pathogenic on $A$. thaliana (Narusaka et al. 2004; O'Connell et al. 2004). Spray- or droplet-inoculation of Arabidopsis Col-0 plants with a conidial suspension of two $C$. higginsianum isolates (MAFF305635 and MAFF305970) resulted in either complete collapse of the plants (Fig. 1A) or severe lesions at inoculation sites (Fig. 1B) at 7 days postinoculation (dpi). In contrast, inoculation with the nonadapted $C$. lagenarium isolate 104-T, which in nature infects cucumber, did not prompt macroscopically visible symptoms (Fig. 1A and B). Similarly, C. truncatum MAFF425349 and C. gloeosporioides S9275, pathogens of green soybean and mulberry, respectively, formed no visible lesions (Fig. 1B). These results suggest that $C$. lagenarium, $C$. truncatum, and $C$. gloeosporioides are all nonadapted pathogens on Arabidopsis. Microscopic analysis revealed that $C$. higginsianum formed melanized appressoria within $12 \mathrm{~h}$, and intracellular primary hyphae were visible in attacked plant cells at 2 dpi (Fig. 2A). At 4 dpi, we recorded the presence of primary hyphae at penetration sites of both $C$. higginsianum isolates MAFF305635 and MAFF305970 (84.4 $\pm 4.3 \%$ and $68.2 \pm 7.9 \%$, respectively), demonstrating efficient invasion by this adapted pathogen. At $7 \mathrm{dpi}$, the $C$. higginsianum strains developed a dense mycelium of necrotrophic secondary hyphae inside plant leaves (Fig. 2B). The timing of appressorium development of the three nonadapted Colletotrichum species
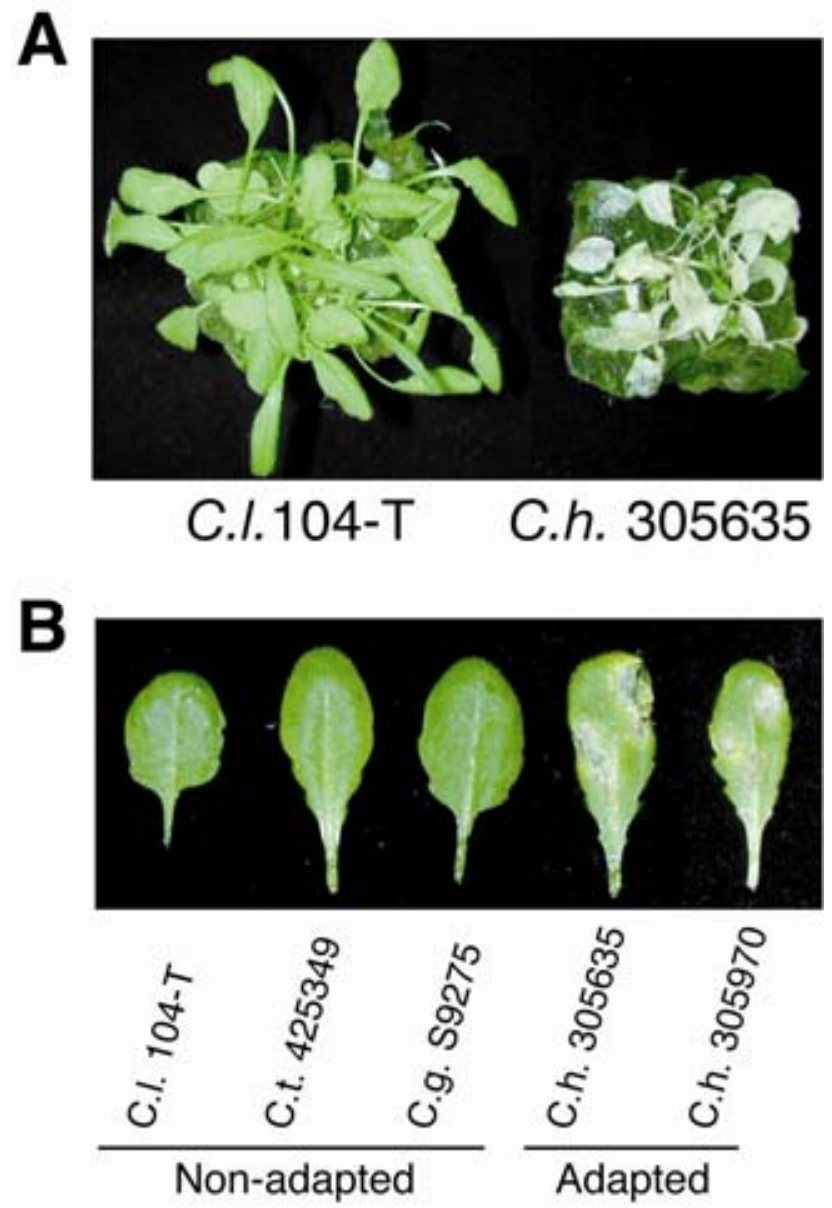

Fig. 1. Infection assay of Arabidopsis thaliana Col-0 plants inoculated with adapted and nonadapted Colletotrichum species. A, At 7 days after spray-inoculation with conidial suspension, $C$. higginsianum $(C . h$.) isolate MAFF305635 caused collapse of the whole plant, whereas $C$. lagenarium (C. l.) isolate 104-T did not cause any visible lesions. B, Failure of infection of three Colletotrichum isolates on A. thaliana. C. lagenarium 104-T, C. truncatum (C. t.) MAFF425349, C. gloeosporioides (C. g.) $\mathrm{S} 9275, C$. higginsianum MAFF305635, and $C$. higginsianum MAFF305970 were inoculated on Arabidopsis. Conidial suspensions of each isolate were drop-inoculated onto leaves of A. thaliana Col-0 and were incubated for 7 days. The $C$. higginsianum isolates formed necrotic lesions on inoculated leaves, whereas the C. lagenarium, C. truncatum, and $C$. gloeosporioides isolates failed to form lesions. 
was similar to that of $C$. higginsianum (i.e., within $12 \mathrm{~h}$; data not shown). Likewise, appressoria of the nonadapted species were highly pigmented with melanin, which is indicative of their functionality. However, in contrast to $C$. higginsianum, the nonadapted Colletotrichum species failed to develop intracellular primary hyphae (Fig. 2C and D and data not shown). Absence of trypan blue stain inside epidermal cells beneath appressoria formed by $C$. lagenarium and $C$. gloeosporioides suggests that the attacked plant cells remained alive (at $7 \mathrm{dpi}$; Fig. 2C and data not shown). Plant cell viability was corroborated by plasmolysis assays (data not shown). Thus, if termination of pathogenesis in the nonhost interactions involves induced plant resistance responses, these must be executed without cell death. However, trypan blue precipitate was occasionally seen in epidermal cells attacked by $C$. truncatum at 7 dpi, suggesting that this nonadapted fungus can trigger plant cell death (Fig. 2D). This cell death is not the consequence of C. truncatum invasion, since primary hyphae were not visible inside the dye-stained epidermal cells. Also, this species often formed lesions on A. thaliana when conidia were inoculated at higher concentrations, although primary hyphae were hardly observed inside lesions (data not shown). Collectively, our data suggest that the nonadapted Colletotrichum species fail to switch from surface to invasive growth.
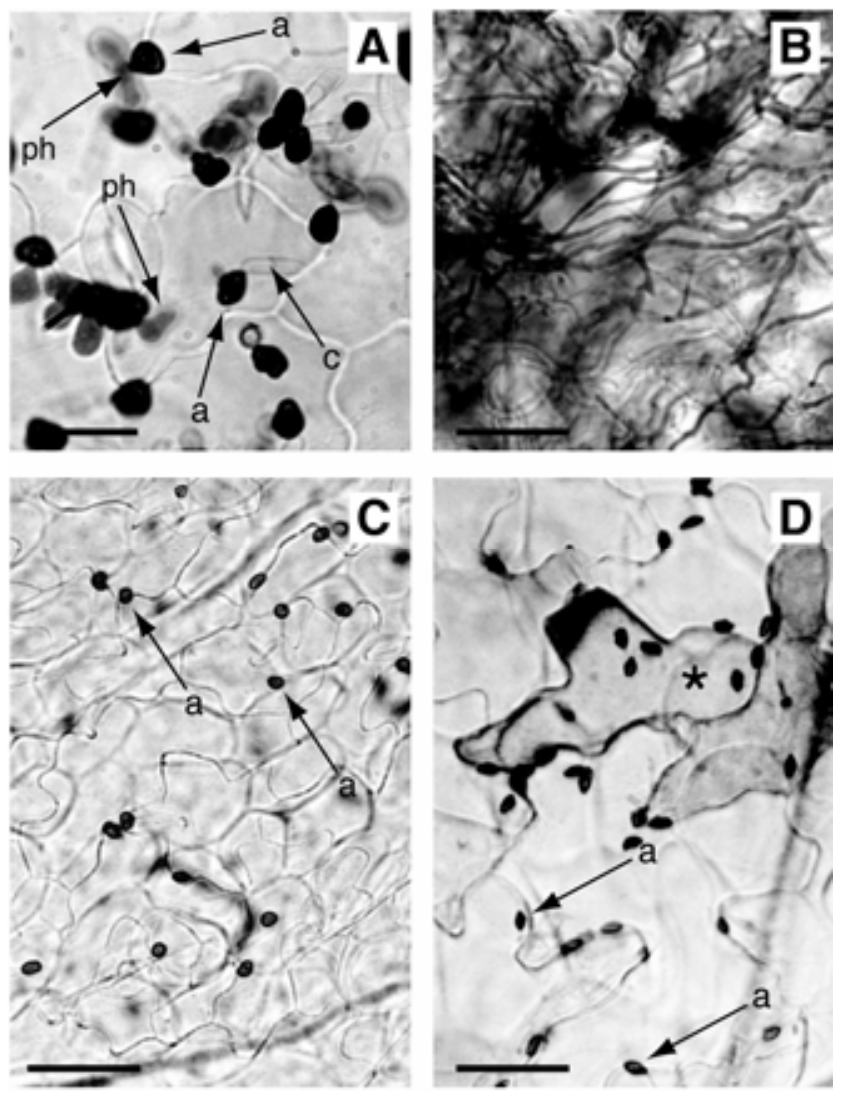

Fig. 2. Preinvasion resistance of Arabidopsis against nonadapted Colletotrichum species. Conidial suspensions were drop-inoculated on A. thaliana Col-0. Inoculated leaves were stained with lactophenol trypan blue. $a=a p-$ pressorium, $\mathrm{c}=$ conidium, and $\mathrm{ph}=$ primary hypha. A, Appressoria of the adapted pathogen $C$. higginsianum have penetrated epidermal cells to form intracellular primary hyphae. Leaves inoculated by $C$. higginsianum 305635 were incubated for 2 days. B, Necrotrophic growth of $C$. higginsianum. Leaves inoculated by $C$. higginsianum 305635 were incubated for 7days. C and D, Penetration failure of the nonadapted Colletotrichum species. Leaves inoculated by $C$. lagenarium 104-T (C) and $C$. truncatum 425349 (D) were incubated for 7 days. An asterisk indicates a dead epidermal cell stained by trypan blue. Bar in $\mathrm{A}=20 \mu \mathrm{m}$. Bars in B through $\mathrm{D}=$ $50 \mu \mathrm{m}$.
Both adapted and nonadapted Colletotrichum species induce papillary callose formation.

CWA formation beneath fungal appressoria is a widespread plant response in interactions with diverse fungal and bacterial parasites (Brown et al. 1998; Kobayashi et al. 1992; ThordalChristensen et al. 1997). Although CWA formation is generally interpreted as an induced resistance response to fungal invasion, individual CWA components may serve other roles (Jacobs et al. 2003; Nishimura et al. 2003). We investigated CWA formation in Arabidopsis epidermal cells upon inoculation with the three nonadapted Colletotrichum species and visualized one CWA component, papillary-associated callose, by aniline blue staining at 24 hours postinoculation (hpi). UV-induced fluorescence with the aniline blue fluorochrome was readily detectable in plant cells beneath Colletotrichum appressoria (Fig. 3A). These fluorescence signals were very weak in a pmr4 mutant background that is specifically impaired in the accumulation of papillary callose (Jacobs et al. 2003; Nishimura et al. 2003), indicating that the detected fluorescence signals report genuine papillary callose (Fig. 3A). The PMR4/GSL5-dependent callose production beneath Colletotrichum appressoria suggests that Arabidopsis epidermal cells detect and respond to entry attempts of the nonadapted anthracnose fungus. Closer examination of papillary callose at fungal appressoria revealed two patterns (Fig. 3B). One pattern is characterized by extensive callose accumulation in an area surrounding appressoria, designated large-type papillary callose (LPC), while the second form is characterized by a more localized, punctate accumulation, designated small-type papillary callose (SPC). It is possible that the area of callose accumulation is an indicator of the actual size of CWA. We quantified the incidence of papillary callose upon inoculation with the three tested nonadapted Colletotrichum species. At 24 hpi, more than $70 \%$ of appressoria induced the deposition of callose papillae in attacked epidermal cells (Fig. 3C). Upon C. lagenarium inoculation, the LPC type was found more often than the SPC form ( $48 \%$ and $24 \%$, respectively). This tendency was more pronounced in $C$. truncatum and $C$. gloeosporioides interactions, i.e., we observed mainly the LPC form. In order to compare fungus-triggered callose formation in interactions with adapted and nonadapted Colletotrichum species, we also inspected epidermal cells attacked by virulent $C$. higginsianum strains. Interestingly, the incidence of callose formation as well as the ratio of LPC to SPC was markedly lower in comparison with the nonadapted Colletotrichum (Fig. 3C). This might indicate that virulent Colletotrichum can suppress or bypass the induction of papillary callose.

\section{Papillary callose formation is induced by penetration-peg formation.}

The finding that papillary callose is induced at most attempted entry sites of the nonadapted Colletotrichum species prompted us to examine whether inductive signals are released at a distinct stage during fungal pathogenesis. For these experiments, we used previously isolated and characterized nonpathogenic mutants of $C$. lagenarium isolate 104-T. The aph1 mutant DAP59 and the cst1 mutant RCS2-1 each form melanized appressoria but have defects in subsequent steps required for pathogen entry. While aphl is able to differentiate penetration pegs, the development of this structure is probably affected in the cst 1 mutant (Tsuji et al. 2003). A third mutant, designated 82335 , was also shown to have a defect in penetration-peg formation (Katoh et al. 1988). APH1 encodes a predicted tRNA methyltransferase, $C S T 1$ a putative transcription factor related to yeast STE12, while the molecular lesion in mutant 82335 is unknown (Y. Takano and N. Takayanagi, unpublished data; Tsuji et al. 2003). As expected, each of the tested Colletotrichum mutants formed appressoria on Arabidopsis leaves 
within 12 hpi (data not shown). At 24 hpi, the aphl mutant formed melanized appressoria and triggered papillary callose accumulation, like the parental strain 104-T (Fig. 4B). In contrast, both 82335 and cstl mutants barely induced detectable

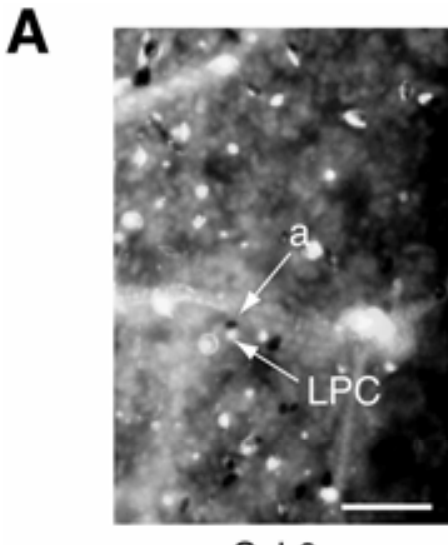

Col-0

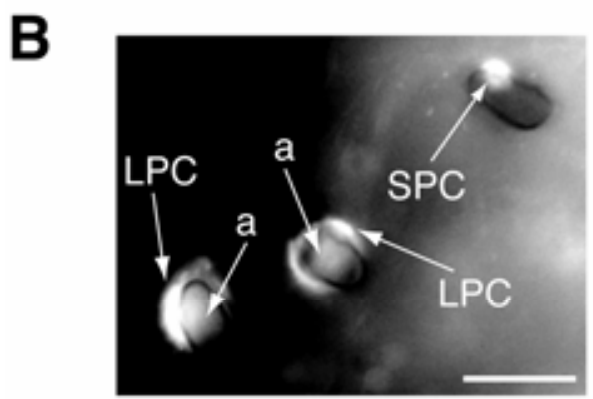

C

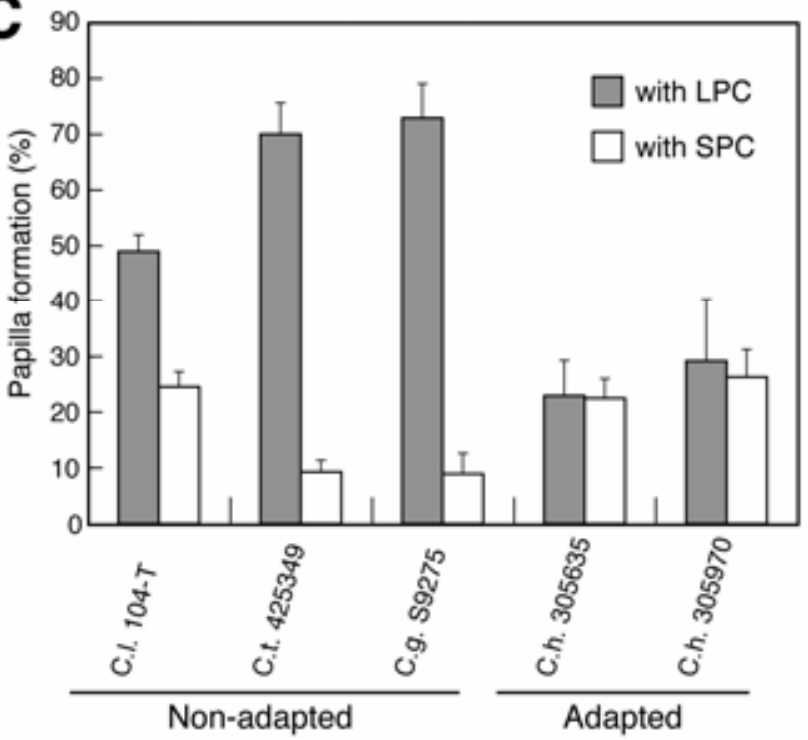

Fig. 3. Papilla formation against Colletotrichum isolates. Conidial suspensions of tested Colletotrichum isolates were inoculated on Arabidopsis thaliana. Inoculated leaves were incubated for $24 \mathrm{~h}$, were stained with aniline blue, and were viewed with epifluorescence microscopy to observe deposition of papillary callose. $\mathrm{a}=$ appressorium, $\mathrm{LPC}=$ large papillary callose, and SPC = small papillary callose. A, PMR4/GSL5-dependent papillary callose deposition of $A$. thaliana Col- 0 against the nonadapted $C$. truncatum isolate 425349 . Bar $=50 \mu \mathrm{m}$. B, Two types of papilla formed beneath appressoria of $C$. truncatum isolate 425349 by A. thaliana Col-0. Papillary callose was investigated by fluorescent microscope with high magnification. Bar $=10 \mu \mathrm{m}$. $\mathbf{C}$, Quantitative analysis of papilla formation by $A$. thaliana Col- 0 against the adapted and nonadapted Colletotrichum species. At least 100 appressoria were observed in each experiment. The mean and standard deviation were calculated from three independent experiments. plant callose production despite effective melanization of appressoria (Fig. 4A and B). We conclude that appressorium formation and melanization of the appressorial cell wall are not sufficient to trigger papillary callose accumulation and hypothesize that cues triggering plant defense responses are specifically released coincident with penetration-peg formation.

\section{Secretion events mediated by the PEN1 syntaxin are not required for preinvasion resistance to nonadapted Colletotrichum species.}

The plasma membrane resident PEN1 syntaxin is required for effective preinvasion resistance to nonadapted powdery mildews, controls timely formation of papillae in response to powdery mildew challenge, and becomes recruited to a plasma membrane microdomain beneath fungal appressoria (Assaad et al. 2004; Bhat et al. 2005; Collins et al. 2003). To assess a potential involvement of PEN1 in nonhost resistance to Colletotrichum, we inoculated the nonadapted $C$. truncatum isolate on
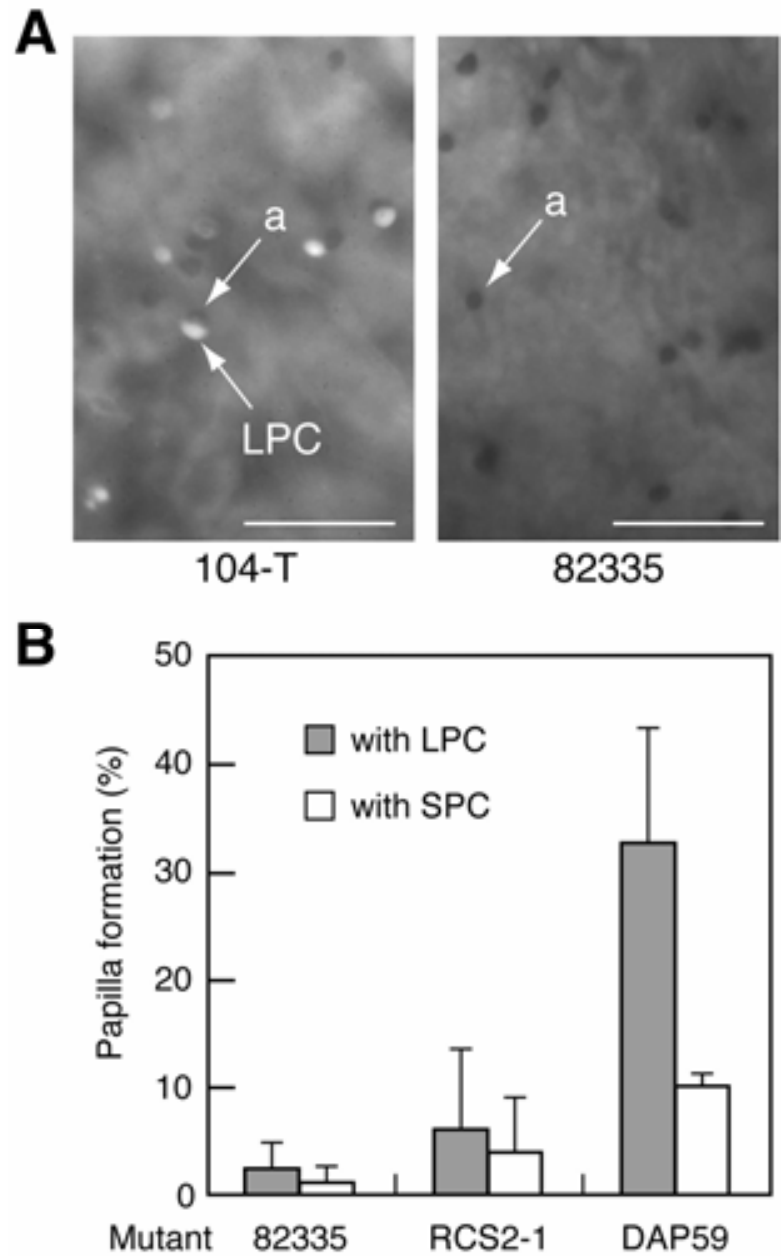

Fig. 4. Colletotrichum lagenarium mutants defective in penetration-peg formation failed to induce papilla. Conidial suspensions of tested mutant strains were inoculated on Arabidopsis thaliana Col-0. Inoculated leaves were incubated for $24 \mathrm{~h}$, and deposition of papillary callose was investigated. 82335, RCS2-1 and DAP59 are mutant strains, defective in appressorial penetration, derived from the $C$. lagenarium wild-type strain 104-T. 82335 and RCS2-1 (cst1) are defective in penetration-peg formation, whereas DAP59 (aph1) retains the ability to develop a penetration peg. A, Lack of callose deposition beneath appressoria of the $C$. lagenarium mutant 82335. a = appressorium; LPC $=$ large papillary callose. Bars $=50 \mu \mathrm{m}$. B, Quantitative analysis of papilla formation in response to the $C$. lagenarium mutants defective in appressorial penetration. At least 100 appressoria were observed in each experiment. The mean and standard deviation were calculated from three independent experiments. 
pen 1-1 null mutant plants. At $24 \mathrm{hpi}$, there was no discernible difference in the frequency of papillary callose in wild-type and pen 1 mutant plants (Fig. 5A). Interestingly, at $10 \mathrm{hpi}$, wild-type plants responded to invasion attempts more often with LPC formation than did penl mutants (52 and $28 \%$ of interaction sites, respectively; Fig. 5A). Similar results were obtained with the pen 1-3 mutant (data not shown). This delay in the formation of papillary callose in response to a nonadapted anthracnose fungus is reminiscent of delayed papilla formation in penl plants upon inoculation with the nonadapted powdery mildew fungus Blumeria graminis (Assaad et al. 2004), suggesting that PEN1 controls timely papilla formation in response to attack by both fungi. However, $C$. truncatum did not form primary hyphae inside epidermal cells of pen1 mutants at either 4 (Fig. 5B) or 7 dpi (data not shown). Likewise, C. lagenarium and $C$. gloeosporioides also failed to invade epidermal cells of penl plants (data not shown), demonstrating that PEN1 syntaxin does not control an entry-limiting step of preinvasion resistance to nonadapted anthracnose fungi.

In contrast to the prominent focal accumulations of PEN1GFP induced during penetration by nonadapted powdery mildews (Assaad et al. 2004), no accumulation of PEN1-GFP was detectable at sites of attempted penetration by $C$. lagenarium
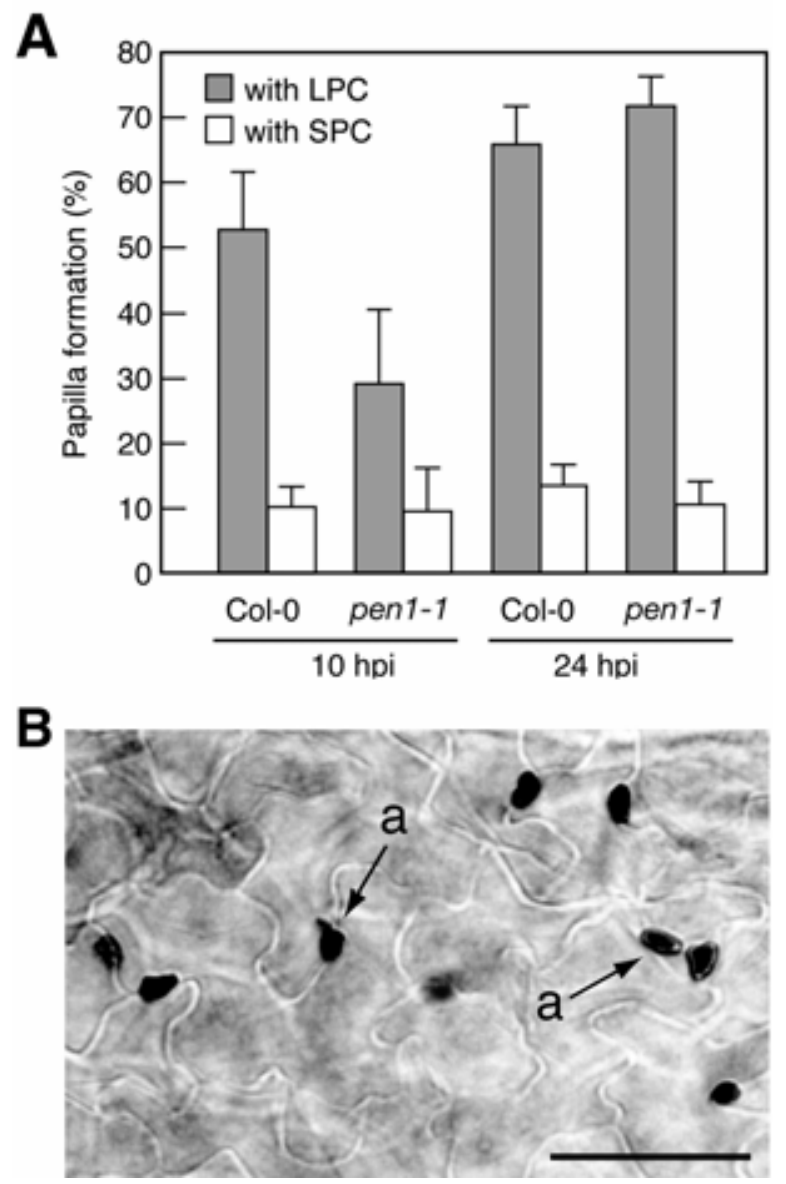

Fig. 5. PEN1 is dispensable for preinvasion resistance against a nonadapted Colletotrichum species. A, Papilla formation in the pen1-1 mutant in response $C$. truncatum isolate 425349 is delayed relative to the wildtype Col-0. Inoculated leaves were incubated for 10 or $24 \mathrm{~h}$ and then were stained with aniline blue for detection of papillary callose. At least 100 appressoria were observed in each experiment. The mean and standard deviation were calculated from three independent experiments. B, The pen 1-1 mutant retains preinvasion resistance against $C$. truncatum. No intracellular primary hyphae had developed in epidermal cells after 4 days. Leaves were stained with lactophenol trypan blue. Bar $=50 \mu \mathrm{m}$. a = appressorium.
104-T, although this region of the plasma membrane was often partially obscured by the darkly melanized appressorium (Fig. 6A and B). Likewise, there was no focal accumulation at sites of successful penetration by $C$. higginsianum. Confocal microscopy showed that, as young intracellular primary hyphae expanded into the cell lumen, they invaginated the host plasma membrane (Fig. 7A and B). At this early stage, the plasma membrane was uniformly labeled by PEN1-GFP and showed a similar fluorescence intensity to the uninvaginated membrane underlying the outer epidermal cell wall. Around larger, older hyphae of $C$. higginsianum, PEN1-GFP labeling remained around the 'neck' region but, with increasing distance from the penetration site, the fluorescence intensity progressively decreased or disappeared entirely from the plasma membrane surrounding the hyphal apices (Fig. 7C and D).

\section{Papillary callose and preinvasion resistance to}

Colletotrichum species requires actin cytoskeleton function.

Plant cells usually respond to attempted fungal entry by rapid disassembly and subsequent polarized reassembly of actin microfilaments towards appressoria contact sites (Kobayashi et al. 1992). An actin network was previously visualized in living cells of transgenic Arabidopsis plants expressing GFP conjugated to the actin binding domain of a mouse talin (Kost et al. 1998). Based on this finding, transgenic Arabidopsis lines expressing GFP fused to a human talin were recently used as a tool to visualize dynamic actin rearrangement upon challenge with oomycete pathogens (Takemoto et al. 2003). To find out whether entry attempts of nonadapted Colletotrichum species trigger actin rearrangements in Arabidopsis, we utilized a transgenic Arabidopsis line expressing a chimeric GFP-mouse talin gene. Inoculation with $C$. truncatum triggered polarization of fine actin microfilaments beneath appressoria contact points at 8 to $10 \mathrm{hpi}$ (Fig. 8A). Focused actin microfilaments exhibited a more intense fluorescence signal compared with cytoplasmic microfilaments in nonattacked epidermal cells (Fig. 8A and data not shown), suggesting that the rearrangement leads to the formation of thicker actin bundles. This phenomenon was also observed upon inoculation with $C$. lagenarium (data not shown). Interestingly, the $C$. lagenarium mutant 82335, which is defective in penetration-peg formation, failed to induce actin rearrangements towards appressoria (data not shown), suggesting that penetration-peg formation is required to trigger both actin rearrangements and papillary callose formation.

To find out whether actin filament function is required for callose accumulation beneath Colletotrichum appressoria, we used
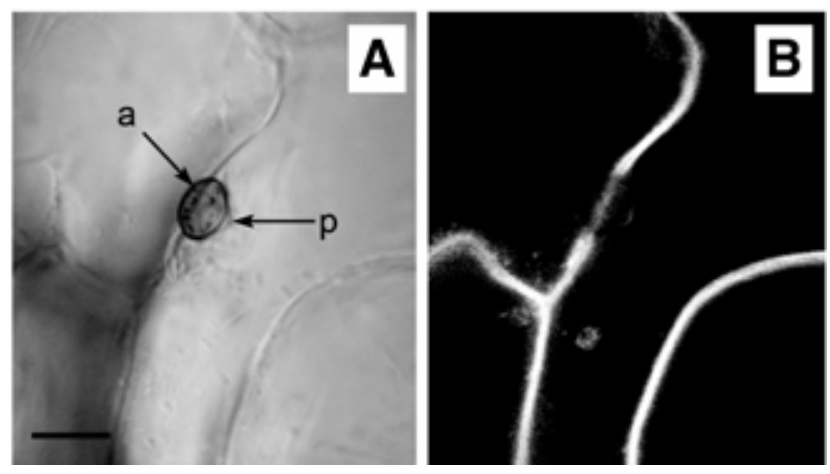

Fig. 6. The distribution of PEN1-green fluorescent protein (GFP) at a penetration site of the nonadapted species Colletotrichum lagenarium. A, Brightfield micrograph showing a small papilla (p) deposited by an Arabidopsis cotyledon epidermal cell beneath the melanized appressorium (a). B, Confocal micrograph showing that, although PEN1-GFP fluorescence is present at the periphery of the papilla, PEN1 does not accumulate at the penetration site. Photos taken three days after inoculation. Bar $=10 \mu \mathrm{m}$. 
a pharmacological approach and infiltrated the microfilament depolymerization factor cytochalasin $\mathrm{E}(\mathrm{CE})$ into the intercellular space of leaves expressing GFP-talin. We infiltrated CE ( 2 or $20 \mu \mathrm{g} / \mathrm{ml}$ ) $30 \mu \mathrm{min}$ prior to spore inoculation of $C$. truncatum. These concentrations were sufficient to trigger actin depolymerization in healthy leaves (not shown). At $24 \mathrm{hpi}$, the lower dose of $\mathrm{CE}$ reduced the LPC incidence and increased the SPC frequency relative to control infiltrations containing $0.02 \%$ dimethyl sulfoxide (DMSO) (Fig. 8B). In the presence of the higher dose of $20 \mu \mathrm{g}$ of $\mathrm{CE}$ per milliliter, we observed a further reduction of the incidence of LPC and SPC, although the corresponding control infiltration (note 10-fold higher DMSO concentration of $0.2 \%$ ) revealed that the DMSO solvent slightly affected the overall incidence of callose formation at interaction sites (Fig. 8B). We infer from these pharmacological experiments that microfilament function might be required for papillary callose formation at attempted Colletotrichum entry sites.

Next, we investigated the effects of CE-mediated actin depolymerization on preinvasion resistance against the nonadapted Colletotrichum species. Leaf infiltration of $2 \mu \mathrm{g}$ of CE per milliliter was sufficient to permit pathogen entry of $C$. truncatum into attacked epidermal cells as indicated by the differentiation of primary hyphae (Fig. 9A). At the higher dose of CE $(20 \mu \mathrm{g} / \mathrm{ml})$, the incidence of $C$. truncatum entry was found to be significantly increased (38\% of interaction sites; Fig. 9A and B). Fungal invasion in the presence of CE was also observed upon inoculation of $C$. lagenarium, although the incidence was lower than in interactions with C. truncatum (Fig.
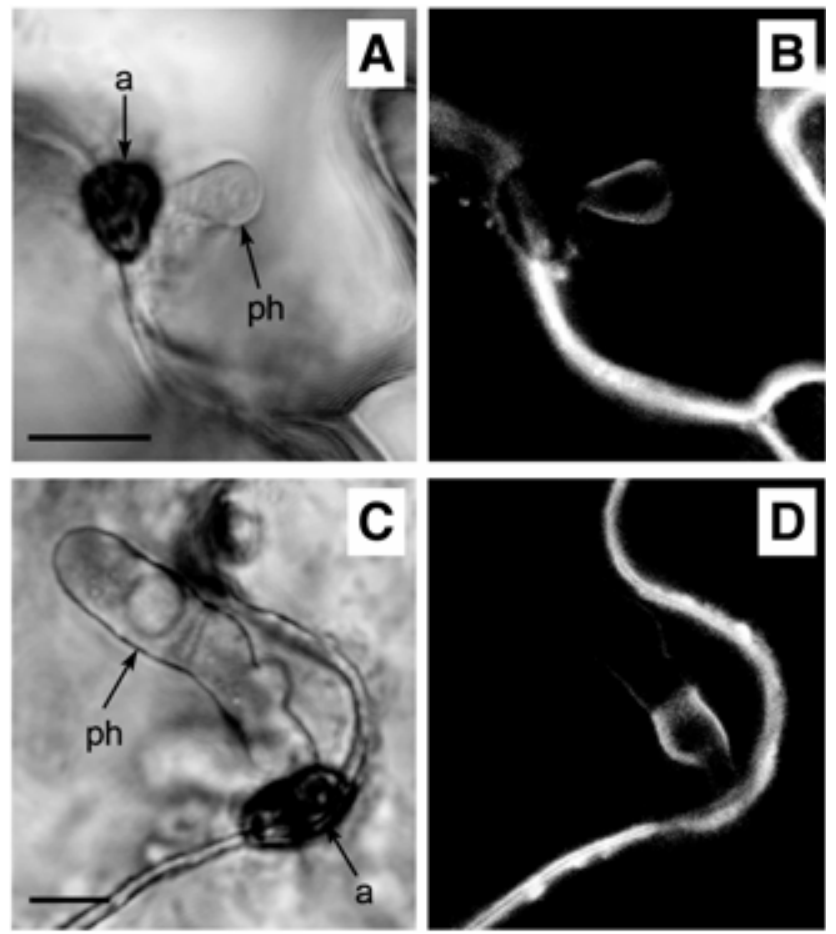

Fig. 7. The distribution of PEN1-green fluorescent protein (GFP) during intracellular development by the adapted species Colletotrichum higginsianum. A, Bright-field micrograph showing a melanized appressorium (a) which has succesfully penetrated an Arabidopsis cotyledon epidermal cell to form a small primary hypha (ph). B, Confocal micrograph showing that PEN1-GFP fluorescence is uniformly distributed throughout the host plasma membrane invaginated around the young primary hypha. $\mathbf{C}$, Bright-field micrograph showing a large intracellular primary hypha inside an Arabidopsis cotyledon epidermal cell. D, Confocal micrograph showing that PEN1-GFP fluorescence is most intense in the invaginated host plasma membrane surrounding the proximal region of the hypha, becoming progressively less intense in the distal region around the hyphal apex. Photos taken two days after inoculation. Bars $=10 \mu \mathrm{m}$.
9A and C). Since CE also inhibits papillary callose formation (discussed above), our findings are consistent with the hypothesis that preinvasion resistance to nonadapted anthracnose fungi is dependent on the actin cytoskeleton.
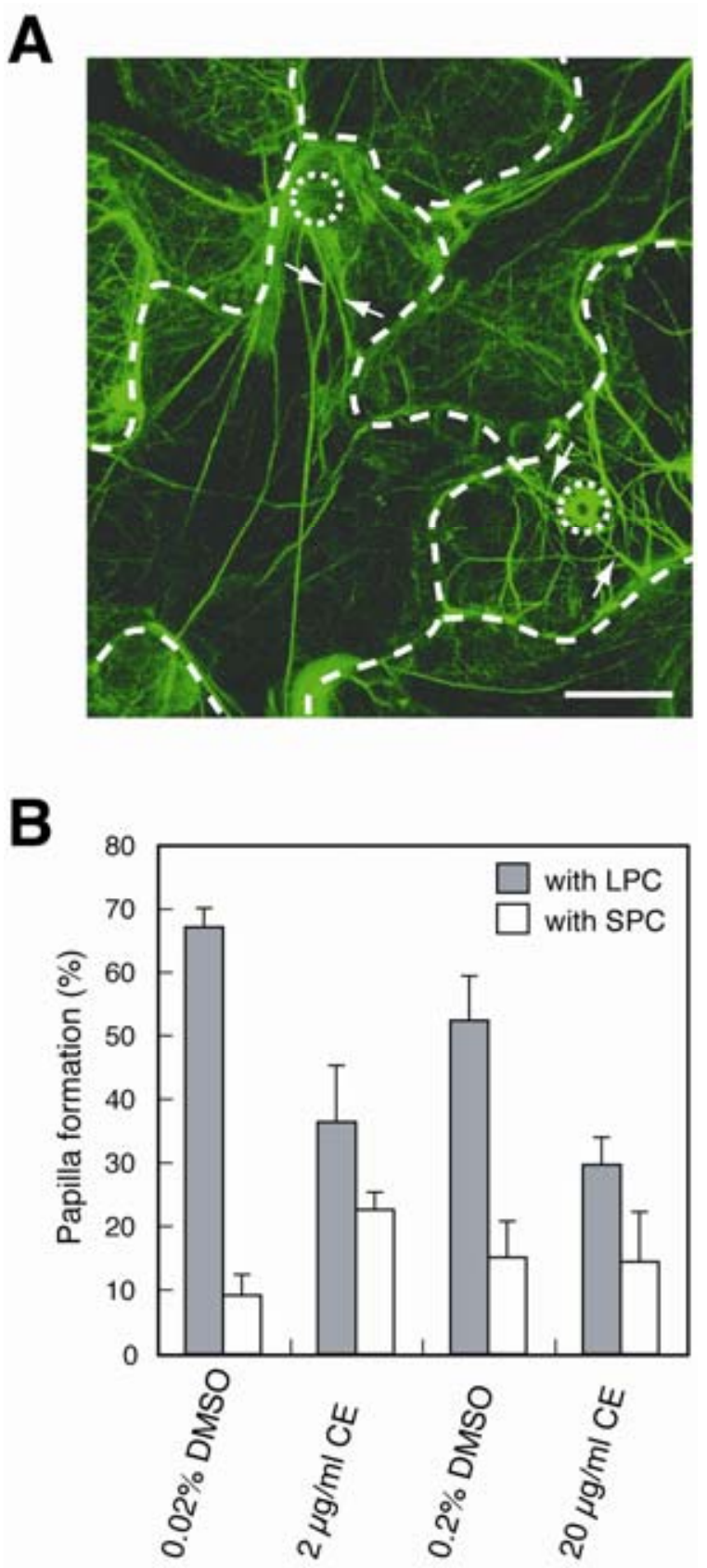

Fig. 8. Microfilaments and papilla formation. A, Rearrangement of microfilaments in Arabidopsis epidermal cells expressing green fluorescent protein fused to the actin-binding domain of a mouse talin (Kost et al. 1998) 8 $\mathrm{h}$ after inoculation with the nonadapted Colletotrichum truncatum isolate 425349. Arrows indicate microfilaments focused on contact sites of appressoria. The junctions between epidermal cells are outlined by dashed lines. Appressoria are indicated by circles drawn by dashed lines. $\mathrm{Bar}=20$ $\mu \mathrm{m}$. B, Cytochalasin E (CE) reduced papilla formation. CE was applied by infiltration into intercellular spaces $30 \mathrm{~min}$ prior to inoculation. dimethyl sulfoxide (DMSO) was used as solvent for CE, i.e., CE solutions at a rate of 2 and $20 \mu \mathrm{g} / \mathrm{ml}$ contain 0.02 and $0.2 \%$ DMSO, respectively. DMSO at each concentration was also infiltrated as a negative control. The C. truncatum isolate 425349 was inoculated on infiltrated leaves, was incubated for $24 \mathrm{~h}$, and was stained with aniline blue. At least 100 appressoria were observed in each experiment. The mean and standard deviation were calculated from three independent experiments. 


\section{DISCUSSION}

We have shown in this study that nonadapted Colletotrichum species form melanized appressoria on Arabidopsis but fail to develop intracellular primary hyphae, suggesting that pathogenesis is terminated during the switch from surface to inva-
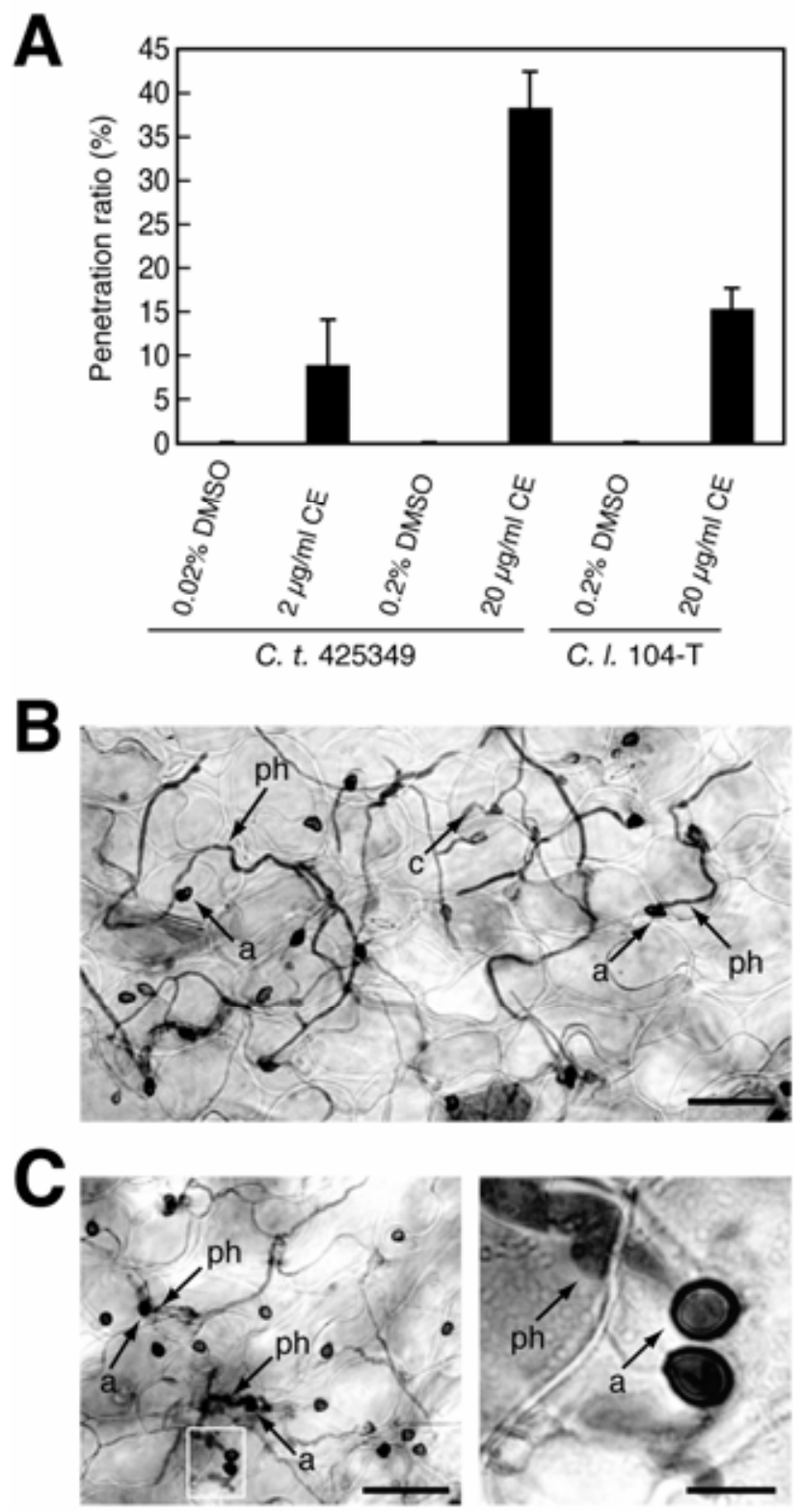

Fig. 9. Inhibition of actin function by cytochalasin E (CE) permitted the nonadapted Colletotrichum species to penetrate Arabidopsis thaliana epidermal cells. A, Penetration assay of the nonadapted Colletotrichum isolates on Arabidopsis treated with CE. CE was applied by infiltration into intercellular spaces $30 \mathrm{~min}$ prior to inoculation. Dimethyl sulfoxide (DMSO) was used as solvent for CE, i.e., CE solutions at 2 and $20 \mu \mathrm{g} / \mathrm{ml}$ contain 0.02 and $0.2 \%$ DMSO, respectively. DMSO at each concentration was also infiltrated as a negative control. The $C$. truncatum $(C . t$.) isolate 425349 or the $C$. lagenarium $(C . l$.) isolate 104-T were inoculated on infiltrated Arabidopsis, were incubated for 4 days, and were stained with lacto phenol trypan blue to observe fungal primary hyphae. At least 100 appressoria were observed in each experiment. The mean and standard deviation were calculated from three independent experiments. B, Penetration of $C$. truncatum into Arabidopsis infiltrated with CE solution $(20 \mu \mathrm{g} / \mathrm{ml})$. a = appressorium; ph $=$ primary hypha. $\mathrm{Bar}=50 \mu \mathrm{m}$. C, Penetration of $C$. lagenarium into Arabidopsis infiltrated with CE solution $(20 \mu \mathrm{g} / \mathrm{ml})$. The right panel represents the magnified image of the area indicated by square in the left panel. Bars $=50 \mu \mathrm{m}$ and $10 \mu \mathrm{m}$, respectively. sive growth. The requirement of actin filament function for pathogenesis termination and coincident inhibition of papillary callose accumulation strongly suggests that pathogen entry is inhibited by an inducible immune response rather than constitutive preformed barriers or lack of potential plant-derived cues triggering invasive growth. The failure of the nonadapted C. lagenarium mutants 82335 and RCS2-1 to induce both papillary callose and plant actin filament polarization revealed penetration-peg formation as the likely trigger of this preinvasion resistance response.

In interactions with nonadapted powdery mildews, PEN1 syntaxin becomes recruited in a plasma membrane microdomain beneath powdery mildew appressoria. CWA formation in the paramural space is delayed in response to attempted powdery mildew entry in pen 1 mutants, and this correlates with impaired preinvasion resistance (Assaad et al. 2004; Bhat et al. 2005; Collins et al. 2003). SYP122, a syntaxin sharing highest sequence similarity to PEN1, also localizes in the plasma membrane at attempted powdery mildew entry sites. However, a syp122 mutant retains preinvasion resistance against the grass powdery mildew fungus, thereby suggesting specific roles for the PEN1 syntaxin in preinvasion disease resistance. We have shown here that papillary callose formation is similarly delayed in penl mutants during infection attempts by nonadapted Colletotrichum species. Thus PEN1 is a plant plasma membrane component involved in localized defense responses against a broad range of fungal pathogens. However, since nonadapted Colletotrichum species failed to invade epidermal cells of pen 1 plants, it appears that the attenuated CWA formation in pen 1 mutants is either still sufficient or is irrele-
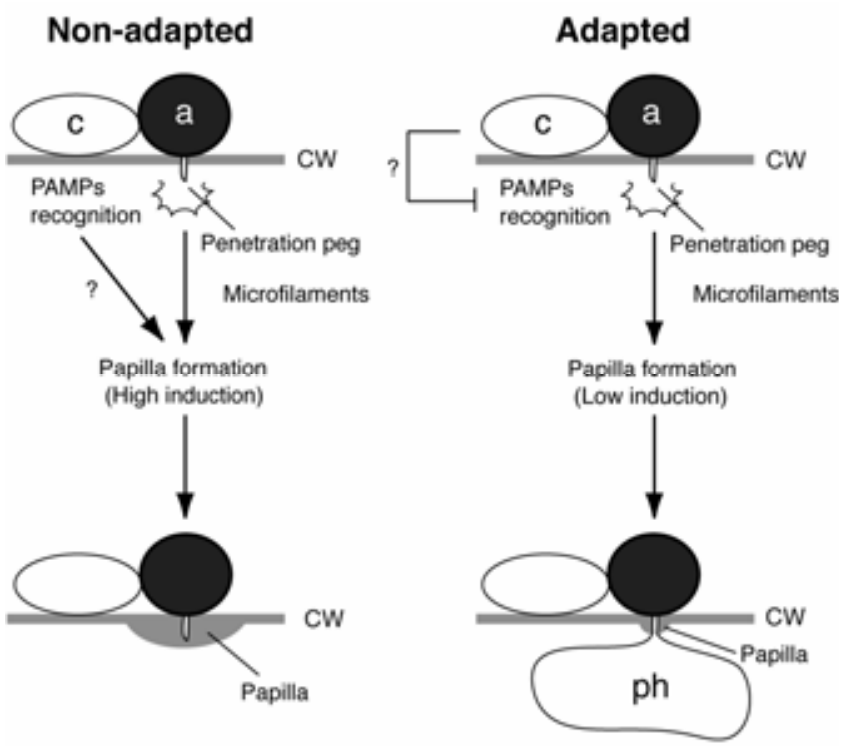

Fig. 10. Hypothetical model of preinvasion resistance and papilla formation in Arabidopsis-Colletotrichum interactions. In nonhost interaction between Arabidopsis and Colletotrichum species, penetration-peg formation by appressoria triggers reorganization of microfilaments and papilla formation. Experiments with cytochalasin E suggest that microfilaments are partially involved in both preinvasion resistance and papilla formation. In host interactions, development of papillae is reduced as compared with nonhost interactions. Both adapted and nonadapted Colletotrichum isolates can develop penetration pegs, suggesting that both types can trigger papilla formation. It is possible that recognition of one or more putative pathogen-associated molecular patterns (PAMP) of Colletotrichum species enhances papilla formation, whereas penetration-peg formation is essential for priming of papilla formation. Thus, reduced papilla formation in host interaction might be due to suppression of PAMP recognition by an unknown factor produced by the adapted pathogen $C$. higginsianum. a = appressorium; $\mathrm{c}=$ conidium; $\mathrm{ph}=$ primary hyphae; and $\mathrm{cw}=$ cell wall. 
vant for termination of anthracnose pathogenesis. Barley ROR2 is the functional homolog of Arabidopsis PEN1 and is required for $m l o$-mediated broad-spectrum resistance against all tested host barley powdery mildew isolates (Collins et al. 2003; Freialdenhoven et al. 1996). However, ROR2 is not essential for resistance against strains of the rice blast fungus $\mathrm{Mag}$ naporthe grisea that can infect barley (Jarosch et al. 2005). The penetration mechanism and hemibiotrophic lifestyle of $M$. grisea is very similar to that of Colletotrichum species, i.e., both parasites develop melanized appressoria that penetrate directly to produce intracellular hyphae inside living plant cells before later switching to necrotrophy (Koga et al. 2004; Perfect et al. 1999). Thus, it appears that PEN1/ROR2 syntaxins do not exert an entry-limiting function in preinvasion resistance to the hemibiotrophic Colletotrichum and Magnaporthe species. Both barley MLO and Arabidopsis AtMLO2 serve as functionally conserved negative regulators of entry resistance to adapted obligate biotrophic powdery mildews (Buschges et al 1997; C. Cansoni, M. Humphrey, S. Somerville, P. SchulzeLefert, and R. Panstruga, unpublished data). Interestingly, loss of MLO (in powdery mildew-resistant mlo mutants) reduces preinvasion resistance to $M$. grisea in barley (Jarosch et al. 2003). This suggests the molecular components of plant preinvasion resistance have both overlapping and distinct functions in controlling the entry of different fungal parasites.

Consistent with the finding that PEN1 is a nonessential component of preinvasion resistance to Colletotrichum species, we detected no evidence for the preferential localization of this syntaxin at penetration sites of either adapted or nonadapted anthracnose fungi. Instead, PEN1-GFP was uniformly distributed in the host plasma membrane around papillae and young intracellular hyphae of $C$. higginsianum. The reduced abundance or exclusion of PEN1 from the plasma membrane surrounding the apical regions of older hyphae suggests that this membrane becomes specialized into two distinct domains. The haustoria of obligate biotrophic fungi and oomycetes are well-known to be enveloped by specialized extrahaustorial membranes (Heath 1992), but this has not been reported previously for the intracellular hyphae of any Colletotrichum species. In the rust and powdery mildew fungi, an impermeable ring called the haustorial neckband tightly binds the host membrane to the fungal cell wall and is believed to demarcate the extrahaustorial membrane from the normal wall-lining plasma membrane (Heath 1992). In the case of $C$. higginsianum, it is unclear how separation of two membrane domains could be maintained, because plasmolysis experiments and transmission electron microscopy observations indicate intracellular hyphae have no structure equivalent to a haustorial neckband (O'Connell et al. 2004). The large expansion of host plasma membrane required to accommodate intracellular hyphae of Colletotrichum species must involve the synthesis and polarized secretion of new membrane material towards the plantfungal interface. However, our results suggest that the PEN1 syntaxin is not essential for this expansion.

We have shown here that actin microfilaments become rearranged toward appressoria of nonadapted Colletotrichum species. CE treatment enabled the nonadapted anthracnose fungi to enter Arabidopsis epidermal cells. This cytochalasin-mediated impairment of preinvasion resistance was previously reported in barley and tobacco against inappropriate pathogens including Colletotrichum species (Kobayashi et al. 1997a and b), suggesting that actin microfilament function plays a general role in preinvasion resistance responses in flowering plants. The requirement of actin filament function for effective preinvasion resistance as well as for papillary callose accumulation might reflect a role of the polarized actin cytoskeleton as a conduit for the vectorial transport of secretory vesicles, and a role for their cargo of either antimicrobial compounds, cell wall precursors, or both towards fungal entry sites. This speculative model is consistent with the proposed secretory function of PEN1 syntaxin during powdery mildew ingress (Assaad et al. 2004; Collins et al. 2003) and the delayed CWA formation at Colletotrichum entry sites observed in this study.

In contrast to the nonadapted Colletotrichum species, the adapted pathogen $C$. higginsianum induced papillary callose at a much lower frequency. In particular, the incidence of LPC was greatly reduced. This might reflect faster penetration-peg formation and entry by the adapted Colletotrichum species, though the timing of appressorium development of $C$. higginsianum is similar if not identical to that of the nonadapted species (data not shown). However, we detected LPC as early as 10 hpi at C. truncatum interaction sites (Fig. 5A), whereas primary hyphae of $C$. higginsianum emerged only after 24 hpi. Thus, the larger deposits of papillary callose might be a consequence of failed fungal entry attempts. For this reason, it is possible that the $C$. higginsianum isolates but not the nonadapted Colletotrichum species can suppress preinvasion disease resistance for many hours before the actual entry process takes place. Basal immunity against bacterial pathogens is triggered by membrane-resident receptors that detect pathogen-associated molecular patterns (PAMP) (Boller 2005). It has been recently reported that two type III bacterial effectors, AvrRpt2 and AvrRpm1, inhibit PAMP-triggered immune responses in Arabidopsis (Kim et al. 2005). Fungal pathogens possess potential PAMP, such as chitin and ergosterol. It is therefore plausible that the genus Colletotrichum possesses one or several PAMP that are recognized by Arabidopsis. Recognition of fungal PAMP might trigger preinvasion nonhost resistance responses to the nonadapted Colletotrichum species, and such PAMP could be released close to the plant plasma membrane by Colletotrichum penetration pegs (Fig. 10). Whether virulent C. higginsianum isolates suppress preinvasion resistance or not remains to be elucidated by future experiments.

\section{MATERIALS AND METHODS}

\section{Fungal culture.}

The $C$. lagenarium wild-type strain 104-T was a stock culture of the Laboratory of Plant Pathology, Kyoto University. The aph1 mutant DAP59 and the mutant 82335 were generated in the same laboratory. The $C$. lagenarium cstl mutant RCS2-1 was provided by Y. Kubo (Kyoto Prefectural University, Japan). Colletotrichum higginsianum isolate IMI 349061 was obtained from CABI Bioscience (Surrey, U.K.). C. higginsianum isolates MAFF305635 and MAFF305970 and the $C$. truncatum isolate MAFF425349 were obtained from the Ministry of Agriculture, Forestry and Fisheries Genebank (Tokyo). The C. gloeosporioides S9275 was provided by S. Yoshida (National Institute for Agro-Environmental Sciences, Tsukuba, Japan). Cultures of the isolates were maintained on potato dextrose agar medium (Difco Laboratories, Detroit) at $24^{\circ} \mathrm{C}$ in the dark. Conidia were obtained by gentle scraping of cultures incubated for 7 to 20 days and filtering through two layers of sterile cheesecloth.

\section{Plant cultivation and inoculations.}

The transgenic Arabidopsis thaliana expressing GFP-talin was provided by N.-H. Chua (Rockefeller University, New York). Seeds of the pmr4 mutant were obtained from the Arabidopsis Biological Resource Center, Ohio State University (Columbus, OH, U.S.A.). Seeds were sown on rockwool, were treated at $4{ }^{\circ} \mathrm{C}$ in the dark for 2 days, and then, were grown in a growth room at $25^{\circ} \mathrm{C}$ with $16 \mathrm{~h}$ of illumination per day in nutrient medium (Dhingra and Sinclair 1985) for approximately 
four weeks. Plants were inoculated by spraying leaves with conidial suspension $\left(2 \times 10^{6}\right.$ conidia per $\mathrm{ml}$ in distilled water $)$ or spotting three $6-\mu$ l drops of conidial suspension $\left(5 \times 10^{5}\right.$ conidia per $\mathrm{ml}$ ) on each leaf. Inoculated plants were placed in a plant-growth box (CUL-JAR300; Iwaki, Tokyo) at $25^{\circ} \mathrm{C}$ with $16 \mathrm{~h}$ of illumination per day and were maintained at $100 \%$ relative humidity. A. thaliana Col-0 plants expressing a PEN1GFP construct under control of the cauliflower mosaic virus $35 \mathrm{~S}$ promoter in the pen 1-1 mutant background (Collins et al. 2003) were grown and inoculated as described previously (O'Connell et al. 2004).

\section{Treatment with CE.}

CE was dissolved in DMSO at $10 \mathrm{mg} / \mathrm{ml}$, and was diluted by water to $2 \mu \mathrm{g}$ of CE per milliliter in $0.02 \%$ DMSO or $20 \mu \mathrm{g}$ of CE per milliliter in $0.2 \%$ DMSO. Solutions were infiltrated into leaf intercellular spaces using a 1-ml syringe 30 min prior to inoculation.

\section{Histochemical staining.}

Plant cell death induced by pathogen inoculation as well as fungal primary hyphae was investigated by staining with lactophenol-trypan blue and destaining in saturated chloral hydrate (Koch and Slusarenko 1990). Material was mounted on a slide in $50 \%$ glycerol and was examined by light microscopy. The penetration ratio (\%) was defined as the number of appressoria forming visible primary hyphae to the number of appressoria $\times 100$. To determine the presence of callose deposits, samples were stained with aniline blue as described by Adam and Somerville (1996). Material was mounted on a slide in $50 \%$ glycerol and was examined with a fluorescence microscope (Zeiss Axioskop, Carl Zeiss, Inc., Oberkochen, Germany) with Zeiss filter set 02 (excitation $365 \mathrm{~nm}$, dichroic $395 \mathrm{~nm}$, emission $420 \mathrm{~nm}$ ). The images were recorded with a CCD camera (CoolSNAP; Roper Scientific, Inc. Tucson, AZ, U.S.A.) and were processed with Adobe Photoshop 7.0 software (Adobe System Inc., Mountain View, CA, U.S.A.). The ratio of papilla formation $(\%)$ was defined as the number of appressoria inducing papilla to the number of appressoria $\times 100$.

\section{Confocal microscopy.}

Actin imaging was performed using an Olympus Fluoview FV500 confocal microscope with a Nikon $60 \times$ PlanApo (1.4 N.A.) oil-immersion objective. Leaves were removed from $A$. thaliana plants expressing GFP-talin and were mounted in water under a coverslip, with the inoculated surface facing the objective lens. Excitation was at $488 \mathrm{~nm}$ and GFP fluorescence was recorded between 505 and $525 \mathrm{~nm}$. To image PEN1-GFP fluorescence, whole cotyledons were excised from 10-day-old seedlings and were mounted in $0.01 \%$ (wt/vol) Tween 20 under a coverslip. Confocal images were acquired using a Leica TCS SP2 confocal microscope equipped with a $\times 63$ (1.2 N.A.) waterimmersion objective. Excitation was at $488 \mathrm{~nm}$ and GFP fluorescence was collected between 495 and $520 \mathrm{~nm}$. All images are projections of optical sections taken at $1-\mu \mathrm{m}$ intervals and were processed using Adobe Photoshop 7.0 software.

\section{ACKNOWLEDGMENTS}

We thank N.-H. Chua (Rockefeller University) for providing seeds of Arabidopsis expressing GFP-talin, Y. Kubo (Kyoto Prefectural University) for $C$. lagenarium cst1 mutant RCS2-1, and S. Yoshida (National Institute for Agro-Environmental Sciences) for C. gloeosporioides isolate S9275. We also thank K. Mise for valuable suggestions during the course of this work. This work was supported in part by a grant-in-aid (15028210) for Scientific Research on Priority Area A from the Ministry of Education, Culture, Sports, Science and Technology, Japan, and a grant-in-aid (15780035) for Young Scientists B, and a grant-in-aid (13306005) for Sci- entific Research A from the Japan Society of the Promotion of Science. R. O'Connell, V. Lipka, and P. Schulze-Lefert are supported by grants from the Max Planck Society, Germany.

\section{LITERATURE CITED}

Adam, L., and Somerville, S. C. 1996. Genetic characterization of five powdery mildew disease resistance loci in Arabidopsis thaliana. Plant J. 9:341-356.

Agrios, G.N. 1988. Plant Pathology. 3rd ed. Academic Press, San Diego, CA, U.S.A.

Assaad, F. F., Qiu, J. L., Youngs, H., Ehrhardt, D., Zimmerli, L., Kalde, M., Wanner, G., Peck, S. C., Edwards, H., Ramonell, K., Somerville, C. R., and Thordal-Christensen, H. 2004. The PEN1 syntaxin defines a novel cellular compartment upon fungal attack and is required for the timely assembly of papillae. Mol. Biol. Cell 15:5118-5129.

Bechinger, C., Giebel, K. F., Schnell, M., Leiderer, P., Deising, H. B., and Bastmeyer, M. 1999. Optical measurements of invasive forces exerted by appressoria of a plant pathogenic fungus. Science 285:1896-1899.

Bhat, R. A., Miklis, M., Schmelzer, E., Schulze-Lefert, P., and Panstruga, R. 2005. Recruitment and interaction dynamics of plant penetration resistance components in a plasma membrane microdomain. Proc. Natl Acad. Sci. U.S.A. 102:3135-3140.

Boller, T, 2005. Peptide signaling in plant development and self/non-self perception. Curr. Opin. Cell Biol. 17:116-122.

Brown, I., Trethowan, J., Kerry, M., Mansfield, J., and Bolwell. G.P. 1998 Localization of components of the oxidative cross-linking of glycoproteins and of callose synthesis in papillae formed during the interaction between non-pathogenic strains of Xanthomonas campestris and French bean mesophyll cells. Plant J. 15:333-343.

Buschges, R., Hollricher, K., Panstruga, R., Simons, G., Wolter, M., Frijters, A., van Daelen, R., van der Lee, T., Diergaarde, P., Groenendijk, J., Topsch, S., Vos, P., Salamini, F., and Schulze-Lefert, P. 1997. The barley Mlo gene: A novel control element of plant pathogen resistance. Cell 88:695-705.

Collins, N. C., Thordal-Christensen, H., Lipka, V., Bau, S., Kombrink, E., Qiu, J. L., Huckelhoven, R., Stein, M., Freialdenhoven, A., Somerville, S. C., and Schulze-Lefert, P. 2003. SNARE-protein-mediated disease resistance at the plant cell wall. Nature 425:973-977.

Dhingra, O., and Sinclair, J. 1985. Basic Plant Pathology Methods. CRC Press, Boca Raton, FL, U.S.A.

Flor, H. H. 1971. Current status for the gene-for-gene concept. Annu. Rev. Phytopathol. 9:275-296.

Freialdenhoven, A., Peterhansel, C., Kurth, J., Kreuzaler, F., and SchulzeLefert, P. 1996. Identification of genes required for the function of nonrace-specific mlo resistance to powdery mildew in barley. Plant Cell 8:5-14.

Heath, M. C. 1992 Structural changes at the plant-fungal interface. Int. J. Plant Sci. 153:S182-S189.

Heath, M. C. 2000. Non-host resistance and nonspecific plant defenses. Curr. Opin. Plant Biol. 3:315-319.

Howard, R. J., Ferrari, M. A., Roach, D. H., and Money, N. P. 1991. Penetration of hard substrates by a fungus employing enormous turgor pressures. Proc. Natl. Acad. Sci. U.S.A. 88:11281-11284.

Jacobs, A. K., Lipka, V., Burton, R. A., Panstruga, R., Strizhov, N., Schulze-Lefert, P., and Fincher, G. B. 2003. An Arabidopsis callose synthase, GSL5, is required for wound and papillary callose formation. Plant Cell 15:2503-2513.

Jarosch, B., Jansen, M. M., and Schaffrath, U. 2003. Acquired resistance functions in mlo barley, which is hypersusceptible to Magnaporthe grisea. Mol. Plant-Microbe Interact. 16:107-114.

Jarosch, B., Collins, N. C., Zellerhoff, N., and Schaffrath, U. 2005. RAR1, $R O R 1$, and the actin cytoskeleton contribute to basal resistance to Magnaporthe grisea in barley. Mol. Plant-Microbe Interact. 18:397-404.

Katoh, M., Hirose, I., Kubo, Y., Hikichi, Y., Kunoh, H. Furusawa, I., and Shishiyama, J. 1988. Use of mutants to indicate factors prerequisite for penetration of Colletotrichum lagenarium by appressoria. Physiol. Mol. Plant Pathol. 32:177-184.

Kim, M. G., da Cunha, L., McFall, A. J., Belkhadir, Y., Debroy, S., Dangl, J. L., and Mackey, D. 2005. Two Pseudomonas syringae type III effectors inhibit RIN4-regulated basal defense in Arabidopsis. Cell 121:749-759.

Kobayashi, I., Kobayashi, Y., Yamaoka, N., and Kunoh, H. 1992. Recognition of a pathogen and a nonpathogen by barley coleoptile cells. III. Responses of microtubules and actin filaments in barley coleoptile cells to penetration attempts. Can. J. Bot. 70:1815-1823.

Kobayashi, Y., Kobayashi, I., Funaki, Y., Fujimoto, S., Takemoto, T., and Kunoh, H. 1997a. Dynamic reorganization of microfilaments and microtubules is necessary for the expression of non-host resistance in barley coleoptile cells. Plant J. 11:525-537. 
Kobayashi, Y., Yamada, M., Kobayashi, I., and Kunoh, H. 1997b. Actin microfilaments are required for the expression of nonhost resistance in higher plants. Plant Cell Physiol. 38:725-733.

Koch, E., and Slusarenko, A. 1990. Arabidopsis is susceptible to infection by a downy mildew fungus. Plant Cell 2:437-445.

Koga, H., Dohi, K., Nakayachi, O., and Mori, M. 2004. A novel inoculation method of Magnaporthe grisea for cytological observation of the infection process using intact leaf sheaths of rice plants. Phyisol. Mol. Plant Pathol. 64:67-72.

Kost, B., Spielhofer, P., and Chua, N. H. 1998. A GFP-mouse talin fusion protein labels plant actin filaments in vivo and visualizes the actin cytoskeleton in growing pollen tubes. Plant J. 16:393-401.

Martin, G. B. 1999. Functional analysis of plant disease resistance genes and their downstream effectors. Curr. Opin. Plant Biol. 2:273-279.

Narusaka, Y., Narusaka, M., Park, P., Kubo, Y., Hirayama, T., Seki, M., Shiraishi, T., Ishida, J., Nakashima, M., Enju, A., Sakurai, T., Satou, M., Kobayashi, M., and Shinozaki, K. 2004. RCH1, a locus in Arabidopsis that confers resistance to the hemibiotrophic fungal pathogen Colletotrichum higginsianum. Mol. Plant-Microbe Interact. 17:749-762.

Nishimura, M. T., Stein, M., Hou, B. H., Vogel, J. P., Edwards, H. and Somerville, S. C. 2003. Loss of a callose synthase results in salicylic acid-dependent disease resistance. Science 301:969-972.

O'Connell, R., Herbert, C., Sreenivasaprasad, S., Khatib, M., EsquerreTugaye, M. T., and Dumas, B. 2004. A novel Arabidopsis-Colleto- trichum pathosystem for the molecular dissection of plant-fungal interactions. Mol. Plant-Microbe Interact. 17:272-282.

Perfect, S. E., Hughes, H. B., O’Connell, R. J., and Green, J. R. 1999. Colletotrichum: A model genus for studies on pathology and fungal-plant interactions. Fungal Genet. Biol. 27:186-198.

Schulze-Lefert, P. 2004. Knocking on heaven's wall: Pathogenesis of and resistance to biotrophic fungi at the cell wall. Curr. Opin. Plant Biol. 7:377-383.

Takemoto, D., Jones, D. A., and Hardham, A. R. 2003. GFP-tagging of cell components reveals the dynamics of subcellular re-organization in response to infection of Arabidopsis by oomycete pathogens. Plant J. 33:775-792.

Thordal-Christensen, H. 2003. Fresh insights into processes of non-host resistance. Curr. Opin. Plant Biol. 6:351-357.

Thordal-Christensen, H., Zhang, Z., Wei, Y., and Collinge, D. 1997. Subcellular localization of $\mathrm{H}_{2} \mathrm{O}_{2}$ in plants. $\mathrm{H}_{2} \mathrm{O}_{2}$ accumulation in papillae and hypersensitive response during the barley-powdery mildew interaction. Plant J. 11:1187-1194.

Tsuji, G., Fujii, S., Tsuge, S., Shiraishi, T., and Kubo, Y. 2003. The Colletotrichum lagenarium Ste12-like gene CST1 is essential for appressorium penetration. Mol. Plant-Microbe Interact. 16:315-325.

Yamaguchi, I., and Kubo, Y. 1992. Target sites of melanin biosynthesis inhibitors. Pages 101-118 in: Target sites of fungicide action. W. Koller eds. CRC Press, London. 